\title{
Toward Authentic Family Engagement with Counter-Narrative and Self-Determination
}

\author{
Deborah Wasserman \\ Lifelong Learning Group at COSI, USA \\ Ayize Sabater \\ Morgan State University, USA
}

\begin{abstract}
Education scholars have demonstrated that family engagement contributes to academic success for urban children. To date, engagement models have invited families into schools. This paper presents an alternative model that invites schools into communities where families use culturallygrounded counter-narrative and self-determination to establish meaningful instances of authentic family engagement. Derived from the Youth Resiliency Institute's Journey Project (Wasserman, Sabater, and Hill, 2017), this paper grounds the model in the relevant literature and explores relationships between the model's theoretical components.
\end{abstract}

Keywords: counter-narrative, culturally relevant pedagogy, family engagement, selfdetermination

\section{INTRODUCTION/BACKGROUND}

Educators have learned that family engagement in children's education contributes to children's academic success (Christenson, Reschly, \& Wylie, 2012; Goodall \& Montgomery, 2014). Thus, to close learning gaps between Black and Caucasian children, educators seek ways to engage parents of low-income Black communities (Potter \& Morris, 2017). One such project has been the Youth Resiliency Institute's Journey Project. As the result of the program's evaluation, Wasserman, Sabater, and Hill (2017) presented an innovative model for a community-centric, culturally based family engagement approach. In this article, we further the use of the model by presenting literature that supports and further develops the relationships between the model's components. This model contributes to existing literature which, to date, has focused on an institutionally based model, i.e., one that invites parents into schools. Our model invites schools into communities. We introduce a community-based alternative in which low-income Black communities use culturally grounded counter-narrative and their own self-determination to establish more meaningful instances of authentic family engagement.

Family engagement in children's education is an important predictor of academic success (Epstein et al., 2009; Wilder, 2016) and has become a priority for educational institutions and the institutions that fund them. Engaging low-income Black families has been particularly 
challenging to educators (Jeynes, 2011). Unfortunately, descriptions of engagement easily can be interpreted in ways that blame families themselves. Consider, for example, statements such as "parents who believe their only role is to get children to school...will not be willing to be involved in school-based or home-based [parental involvement]" (Hornby \& Lafaele, 2011, p. 39). Explanations like this create false and detrimental narratives among both educators and families. For educators, these narratives generate enduring notions of "disengaged" parents as irresponsible and uncaring. In turn, for families, they generate a sense of resentment and disempowerment. In this paper, we present the Journey Project model for meeting family engagement challenges in a way that honors families and promotes their process of creating a more authentic and empowering narrative that draws from their rich experience and strength.

the Baltimore City-based Youth Resiliency Institute's Journey Project began in 2013 with funding from by the W.K. Kellogg Foundation's initiative for family engagement in early childhood education., . As a community-centered family engagement project, the Journey Project continues to function in Baltimore City, Maryland and East Cleveland, Ohio. Community organizer and project director Fanon Hill guides the project with a commitment to five founding principles: (1) any family engagement effort must start with the families themselves; (2) in Black communities "family" is a fluid term defined by sense of bonding; (3) in low-income Black communities, central figures or "guardians of the generations" function as parent figures and often hold strong but informal power and sway and work tirelessly to enhance their communityfamily's conditions (Wasserman \& Hill, 2016); (4) the arts are integral to both bonding and counter-narrative; and (5) Black parents care deeply for the well-being of their children-a seemingly obvious fact, but one that is essential to the counter-narrative, that is central to this model. These principles function within and around the terms further define each of these terms in the glossary in Table 1.

Table 1. A glossary of terms used in this article.

\section{A Glossary of Terms}

Authentic family engagement derives from Auerbach's (2010) explanation of "authentic partnerships," which are described as "respectful alliances among educators, families, and community groups that value relationship building, dialogue, and power sharing" (Auerbach, 2010 , p. 729). Similarly "authentic family engagement" involves interaction within families to further academic success, but it also includes the extended community "family" which also can affect learning institutions, community structures, and policy.

Counter-narratives are explanations of how a culture is organized that replace explanations created by a more dominant group's understanding of itself as central.

Diaspora space is a phrase used by Journey Project director Fanon Hill (Wasserman \& Hill, 2016) to describe a social, psychological, and physical condition that functions as a cultural, identity-giving 'center of gravity,' allowing for simultaneous existence of multiple centers across settings where vulnerable children learn and develop. Through the perpetuation of "Diaspora spaces," cultural identity is remembered, preserved and passed down through language, ritual, art and other practices, thus honoring the traditions of academic achievement, healthy cultural identity, expectations for success, etc., that have incubated Black families in America. 


\section{A Glossary of Terms}

Diaspora-space families consist of a group of caring, nurturing relationships between individuals both within and across blood lines. Terms used to describe bloodline relationships (e.g., sister, brother, Auntie, Mama) apply to any of these relationships. These relationships and the system that emerges from them serve to communicate the Diaspora space counternarrative messages.

Guardians of the generations are strong central figureheads around which a Diaspora space family functions. These central figures hold in common seven characteristics: (1) they are committed to passing through the generations a sense of family and community (as expressed in the Kwanzaa principle of Umoja or 'unity'); (2) they command respect and provide counternarrative; (3) they are committed to the authentic selves and self-determination of the children and adults in their communities; (4) they provide unconditional love with straight talk and high expectations; (5) they function in a parental role to both adults and children; (6) they feel personally and naturally committed to the role (and often have had a parent who functioned in a similar position; and (7) they are spokespeople for the children in their care.

Self-determination is a measure of the quality (and indirectly, the quantity) of human motivation based on level of satisfaction of the three basic psychological needs: sense of competence (I am able to achieve what I set my mind to achieving); sense of relatedness (I care about others, they care about me); and sense of autonomy (my choice-making process is free from tension, pressure, or ambiguity; I make choices in line with my sense of self). These basic psychological needs have been shown to be consistent across developmental age groups and cultures; however,across these groups, the behaviors and conditions that engender this satisfaction differ. These needs persist at a community level and are expressed with pluralsubject statements such as "We are able to achieve what we set our minds to achieving;" "we care about each other;" and "the choices we make for ourselves and our community align with our sense of who we and what we want when we are free from tension, pressure, and ambiguity."

In three communities (East Cleveland, Ohio and Baltimore City, Maryland's Cherry Hill and Albemarle Square), the Journey Project has identified central "guardians," listened to them, and supported their work with "cultural armor" that emerges from African Rites-of-Passage traditions (Wasserman \& Hill, 2016). Central to these traditions are a symbiotic relationship between community, elders, and youth (Blumenkrantz \& Wasserman, 1998). The community nurtures the children in order to hear, and respond to, and be guided by their messages, which manifest when those same children mature into adults and elders. Children thrive because of community; the community thrives because of the messages well-nurtured children will one day deliver (Blumenkrantz \& Wasserman, 1998). An in-depth case study of the Cherry Hill Journey Project (Wasserman et al., 2017) revealed a model useful for future efforts to engage low-income Black communities in their children's education.

The Model consists of three components (Figure 1): Counter-narrative leads to selfdetermination (the Kwanzaa principle of Kujichagulia), and ultimately to authentic family engagement in children's education. Counter-narrative both stimulates and results from interactions with processes of cultural armor and bonding. 


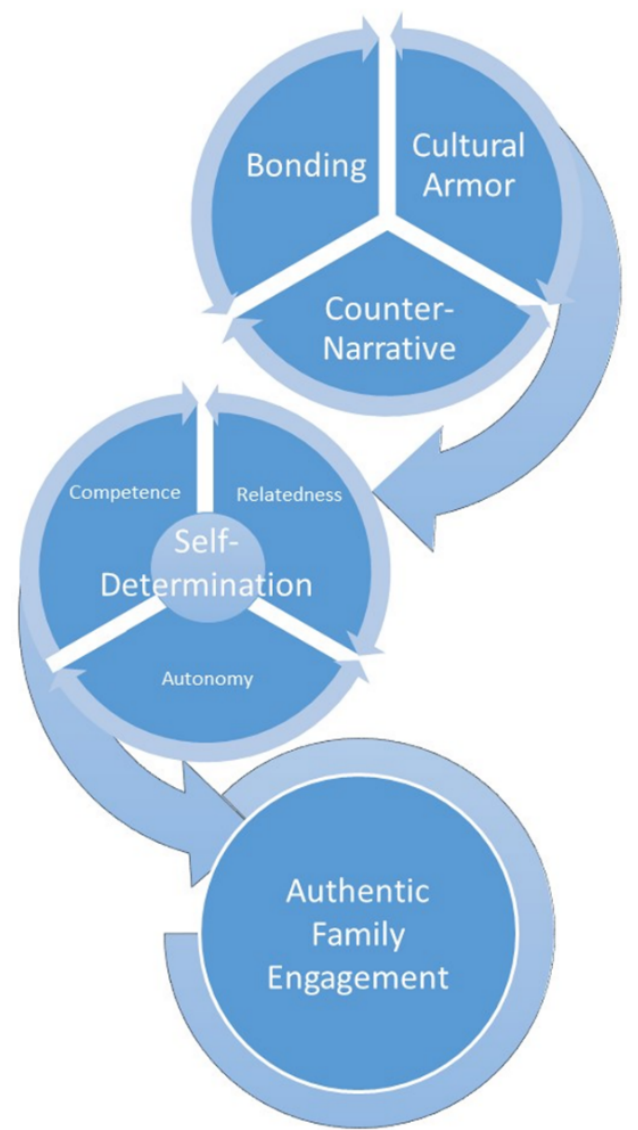

Figure 1. Journey Project authentic family engagement model: counter-narrative and selfdetermination lead to meaningful authentic family engagement

\section{COUNTER-NARRATIVE, BONDING, AND CULTURAL ARMOR: MUTUALLY REINFORCING PROCESSES}

We use the term "counter-narrative" to describe an empowering explanation that replaces a disempowering one. In other words, an individual's or group's explanation of how their own culture is organized replaces an explanation created by a more dominant group's understanding of itself as central. According to Bamberg and Andrews (2004), counter-narratives are stories that people both tell and live; they function as a form of battle against a dominant "master narrative" that marginalizes a particular segment of a population. These master narratives perpetuate pervasive, often stereotypical, and generally accepted complicit stories for interpreting the world. Master narratives manifest as structural racism and cause crises of internalized oppression. Master narratives operate on the macro-societal level, while complicit stories are micro-individual level concepts that enforce the larger master narrative. In contrast to complicit stories, counter-narrative stories offer both explicit and implicit resistance to dominant narratives. They defy what Bamberg and Andrews refer to as "dominant and hegemonic narratives" (p. 351) and are the "flip side" of complicity." 
The master narrative, too readily adopted by many marginalized peoples, often tells their story in terms of poverty, lack of education, laziness and violence. Consider, for instance, a key historical example introduced by Ronald Reagan: when running for the U.S. Republican presidential nomination in 1976 he referred to marginalized women as 'welfare queens,' perpetuating ever since the dominant narrative that describes marginalized people as lazy and vagrant (Black, Sprague, \& New America, 2016). More recently, presidential candidate Trump likewise corroborated the dominant narrative when he stated that Mexicans were "...bringing drugs. They're bringing crime. They're rapists" (Reilly, 2016).

Complicit narrative, as opposed to counter-narrative, occurs when marginalized individuals form their own personal stories in the context of the master narrative. For example, a father participating in the Journey Project said,

\section{Seldom people [stop and listen to me] because they look at me like "He don't know what he's talking about," and [they] just walk on by. I guess [that's] how my punishment is or something.}

As the Journey families evolved, counter-narrative functioned as the pivotal building block toward self-determination and then engagement. But from a structural perspective, building counter-narrative was the most challenging step in the engagement process. Having been raised in a culture created by community centered around Africentric Rites of Passage (his father Paul Hill, Jr. has directed the National Rites of Passage Institute for more than thirty years), Fanon Hill intuitively brought to his program the processes of bonding and what he labeled "cultural armor." As will be shown, both are integral to this engagement model and can be supported by the literature. According to Bamberg and Andrews (2004), a personal counter-narrative emerges when a person "present[s] one's own claims as to what is valued and relevant" (p. 357). Thus, how a person views his or her own cultural assets is critical to knowing "one's own claims."

\section{Cultural Armor}

Literature supports the concept of cultural armor. Banks (1981) discusses how developing a positive story and self-concept has the potential to "...create equal educational opportunities for all..." (\p. 135). Across the nation many educators use culturally relevant pedagogy as a type of cultural armor. Many others conduct trainings designed to boost cultural competencies in an effort to improve the life outcomes for marginalized populations (e.g., Sabater, 2014). This cultural armor, which Director Hill describes as a "protection garnered from knowing the strength of one's cultural heritage" was inextricably part of the counter-narrative development process (Wasserman et al., 2017, p. 12; see Figure 2).

Culturally relevant pedagogy (CRP) creates a counternarrative that explores and imagines the contributions, assets and achievements developed by marginalized groups. Scholars have credited CRP with several benefits. Ladson-Billings (2009) describes CRP as fortifying the student with the positive aspects of her or his culture, as opposed to the dominant narrative which often reinforce themes of failure and holds a deficit view of the culture of the marginalized. Durden (2008) discusses CRP as emanating from social cultural theories that view learning as a culturally mediated process. If learning is mediated by one's culture and learning is

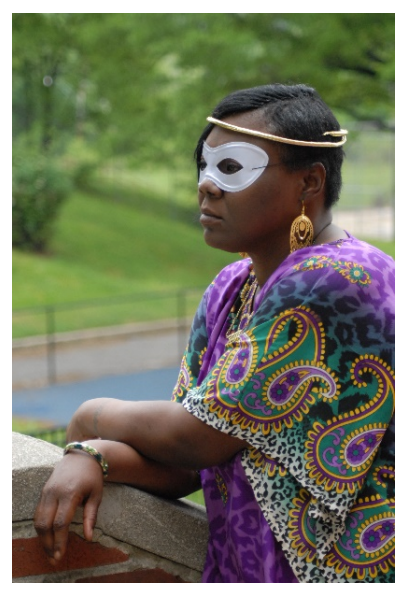


something that influences one's thinking, then it appears important to use culture to affirm a student's identity, or to help shape a student's individual narrative (Durden, 2008). Thus, for marginalized groups, this process of erecting cultural armor creates a narrative that counters the dominant narrative.

In the Journey Project, cultural heritage involves African traditions embodied by the seven, plus one, Kwanzaa principles (unity, self-determination, collective work and responsibility, cooperative economics, purpose, creativity, and faith, plus respect), along with rituals that support them. It also involves recognition of a rich African American culture formed by and in spite of 400 years of relentless oppression. And more locally, it includes recognition of creative and successful historical figures, in this case, of the Cherry Hill community. This cultural armor has also contributed to sense of identity and to Journey Family members' ability to hear and create counter-narrative, which in turn enhanced the bonding between them.

The Journey Project organized around art and culture to mobilize these families. In general, key informant comments showed how learning about African and African American culture provided a sense of pride and "cultural armor." Artistic expression enhanced personal identity both in relation to the self and in relation to unique contributions to the community. Making art and participating in family art-making activities helped create a sense of identity. Through trust-building activities Journey Family members, gained a sense of community and were also recognizing the value of owning their African American heritage and their African roots. However, key informant responses to questions about the value of this identity were mixed -with a connection to African roots being more favorable than African American roots. On the other hand, beneath the ambiguity were signs of a developing pride.

\section{Bonding}

Relationships built through "bonding" support the work of separating from the larger "master narrative". Community based programs, such as the Journey Project, provide a safe place (diaspora space) where the use of bonding fortifies the counter-narrative development process.

Our use of the word, "bonding" derives from the trust-building and identity formation effect associated with a contemporary rites of passage experience, the philosophical and practical model upon which the Journey Project is built. Building on van Gennep's (1960) classic model, Hill, Jr. (1992) describes rites of passage as characterized by three stages: separation, transformation, and incorporation. As part of initiation into a community, new members separate from their former way of existing in community. Then, in the transformation stage, having moved from the familiar to the unfamiliar, through self-discovery they confront and conquer challenges.

In the Journey Project, the bonding process included two essential parts:(1) separation from disempowering stories of self and community, which we call "where-from" stories and (2) trust-building that lays groundwork for transformation. Each contributed to the other and both needed a safe environment to nurture them. Many of the key informant accounts (Wasserman et al., 2017) involved Journey family members finding a welcoming community of people who listened without judgement to these where-from stories - often painfully accompanied by underlying shame and (and largely unfounded) guilt. Trust-building came largely from community family members telling and hearing their where-from stories.

Journey Project key informants spoke of the bonding process in terms of (a) creating a safe environment for understanding and sharing the complexity and origins of disempowerment; (b) trust-building in the context of the Journey family relationships; (c) creating emotional safety necessary for telling and processing these "where-from" stories - as illustrated by the quote in Table 2; (d) guiding young people in the process of creating their own "where-from" stories; (e) 
the effects of this story telling and trust-building; and (f) the advantage of this bonding experience occurring in a community rather than institutional setting.

\section{Table 2. Journey bonding emerged from the safety of sharing "where from" stories.}

I learned because it's other people out there that's going through similar problems than me and since we've been in this program, we feel free to open up and express our feelings among other people. So we don't feel as though we're the only one in the program that go through problems when it's other families like us. We're not the only ones. (Journey Project family member)

In addition to building trust, this transformation experience helps each individual build a sense of personal identity, based on the knowledge of what they have contributed to the group's success. Art-making has been an integral part of the Journey Project's transformation stage, helping Journey family members create their identity. Among the Journey families, this bonding process created receptivity to cultural armor and counter-narrative.

\section{SELF-DETERMINATION}

In the Journey Project, counter-narrative - the new story of pride, strength, and rich cultural heritage-led to self-determination, largely missing from the complicit narrative, but essential to well-being and responsible parenting (Chirkov, M Ryan, \& Sheldon, 2011). Self-determination, one of the seven, plus one, Kwanzaa principles (Kujichagulia), refers to choice making and behavior that is regulated, not by external pressures, but by the intrinsic self. Self-determined behaviors are free from the pressure, tension, and ambiguity that result from denying self in order to respond to an external voice misaligned with the authentic inner one (Koestner \& Losier, 1996). This basic psychological need, for the sense of autonomous self-regulated choice making, is integrally connected to two other basic psychological needs: one for a sense of competence and the other for sense of relatedness (Ryan, 1995). Authentic engagement - engagement that has meaningful outcomes for children, follows self-determination (Deci \& Ryan, 2000; Wasserman, 2010).

Self-determination research supports the inclusion of bonding, cultural armor, and counter-narrative in this engagement model. Multiple studies have demonstrated the highly integrated interdependence of the basic psychological needs for sense of autonomy, relatedness and sense competence (Ryan, 1995; Ryan \& Deci, 2017). Bonding creates relatedness, and cultural armor leads to a sense of competence.

More specifically, causal agency theory, a self-determination sub-theory, posits two types of action necessary for self-determination: volitional and agentic (Shogren, Wehmeyer, \& Palmer, 2017). Volitional action is defined by making a conscious choice; agentic action is action in service to a goal. Together they create "action-control beliefs," a sense of empowerment emanating from a sense of having what it takes to freely choose and achieve goals. Action-control beliefs contrast with causality beliefs that attribute goal achievement, or lack of it, to external factors (Shogren et al., 2015). Movement from external causality beliefs to those of action-control require external supports for personal autonomy (choice making free from tension, pressure or ambiguity).

Countering one's autonomy are thwarting conditions that together emerge from the combination of family, social, institutional, cultural, and economic influences (Ryan \& Deci, 2011). Conditions that support and thwart autonomy both emerge from political systems and 
laws. Even within highly democratic systems, master narratives can exert conditions that thwart sense of autonomy. The interface between and individual self and surrounding environmental contexts (family, community, broader socio-political-structural) create a "carrying capacity" which Little, Snyder, and Whehmeyer (2006) define as "the maximal level of functioning given one's personal resources and the limits and/or supports of the surrounding contexts."

Processes of bonding support a sense of relatedness, and processes of cultural identification and pride support a sense of competence. The combined sense of autonomy and self-determination that emerges from these supports increases carrying capacity by opening the door for the counter-narrative necessary for balancing the autonomy-thwarting conditions and master narratives found in high poverty communities. Self-determination describes the carrying capacity necessary for authentic family engagement with the systems responsible for children's education. It leads to family members volitionally and agentically participating in children's learning institutions where parent engagement may generate the greatest benefits for a child's learning (Goodall and Montgomery, 2014, p. 407).

\section{AUTHENTIC FAMILY ENGAGEMENT}

To define "authentic family engagement" we borrow from the work of scholar and educator Deborah Watson-Hill who, in her (2013) dissertation, distinguished between family engagement and family involvement. Her research demonstrates that although families are perceived as seemingly uninvolved by school administrators in school-sanctioned, school-authored activities, African American parents, in her study, valued education highly and engaged with their children and with schools in ways they believed were most helpful. In the model presented here we expand "authentic family engagement' to include not only interacting within families to further academic success, but also to acknowledge and include diaspora family that also can affect learning institutions, community structures, and policy that guides them.

Within the educational arena there is wide agreement around the need for family and community involvement to improve student learning (Epstein et al., 2009). While many researchers (Domina, 2005; Epstein, 1981; Jeynes, 2016) discuss "parental involvement" as a way to improve educational outcomes for students, other researchers (Auerbach, 2010; Goodall \& Montgomery, 2014; Torre \& Murphy, 2016) interrogate "parental involvement" as being an inadequate concept and discuss other concepts such as "parental engagement." Goodall and Montgomery (2014) argue that "while engagement may be defined as "the feeling of being involved in a particular activity'...[the] feeling of ownership...is greater than...simple involvement." This "means that parental engagement will involve a greater commitment, a greater ownership of action, than will parental involvement" (p. 400). Parent ownership points to the concept of agency because "it relates to the capacity of parents to act (in a beneficial manner) in relation to their children's learning" after parents choose to take action (p. 401).

Goodall and Montgomery (2014) further posit that engagement exists as a continuum, and they present "a model for the progression...[of] parental engagement with children's learning" (p. 399). They proffer that parental involvement is only the first stage of working to improve student learning, which is often one-directional and directed by the school. A second stage of interaction is "parental involvement with schooling", where there is an exchange of information between parents and interested school/community partners concerning the child's learning. Finally, the third stage is parental engagement, which is considered a more robust way to improve student learning where parents (and/or the child) lead the process (Goodall \& Montgomery, 2014, p. 403). For example "as [parents]...move through the continuum, roles shift, so that parents, who merely receive information at the first level, move through levels of 
partnership with school staff until eventually the discussions are parent-led" (Goodall \& Montgomery, 2014, p. 407). Understanding some of the different aspects of parental engagement are important because research demonstrates that it "can boost children's self-esteem, increase motivation and engagement with learning and can lead to increased learning outcomes" (Goodall \& Montgomery, 2014, p. 402).

Understanding and pointing to more robust ways of empowering parents is critically needed given the continued failure of many urban schools in promoting high educational outcomes for all students (Anyon, 1997; Banks, 1981; Darling-Hammond, 2010; Howard, 2010; Ladson-Billings, 2009; Sleeter \& New, 1991). In this vein, Auerbach (2010) points to "possibilities beyond the traditional involvement of parents toward leadership for authentic school-family partnerships" (p. 729) He describes this traditional involvement as follows:

\begin{abstract}
White parents of higher socioeconomic status are more likely to be directly involved-attending school events, volunteering, taking part in governance...By contrast...parents of color and low-income parents are traditionally viewed by educators through a deficit lens, which assumes that they do not care about or support education and which devalues their contributions... [these parents] are often ignored, rebuffed, or silenced by administrators, especially if they challenge policies...whereas White middle-class or upper-class parents receive special attention. (Auerbach, 2010, p. 730)
\end{abstract}

Given the failings of the traditional involvement paradigm, as noted above, Auerbach (2010) calls for "authentic partnerships" [or engagement], which he describes as "respectful alliances among educators, families, and community groups that value relationship building, dialogue, and power sharing" (Auerbach, 2010, p. 729). More research is needed to delve into interventions, such as the Journey Project, that authentically engage parents in student learning to transform the performance of failing urban schools. Imagine, as Auerbach posits, "what if instead of seeking to contain, train, or manage parents in line with school agendas, schools sought out and attended to parent voices?" (Auerbach, 2010, p. 728).

Within this research on optimal school-family partnerships, self-determination has been understood as integral to defining "true partnerships" (Grolnick \& Raftery-Helmer, 2015). More specifically, the most successful partnerships engender self-determination: in their role as educational partners, parents experience themselves as competent, related, and autonomous. So too, do teachers and administrators, who feel parents believe they are effective and supportive. Research has shown that parents who saw themselves as efficacious were more likely to appreciate the effectiveness of the school (Gordon \& Louis, 2009). Additionally, the amount autonomous motivation for involvement is often related to the amount of involvement and to student performance (Grolnick, 2015). These results support the importance of parents feeling involved for their own self-endorsed, self-determined reasons, rather than complying with school agendas and/or external institutional expectations. These findings lead to the importance of educational personnel looking beyond the quantity of involvement (e.g., meeting attendance and volunteering), as those institutions sanction, but instead direct educators to look at the quality of involvement - and more specifically, to the quality of the motivation for involvement in hopes of achieving authentic family engagement.

We believe the model for authentic family engagement that we present in this paper provides one road map for generating self-determined and empowering educational engagement. Our intention is to continue the theory of change dialog about how this authentic engagement takes place. Most important, we believe that any model, whether this or another, seeking to 
authentically engage families from very low income Black communities must honor, and even begin with, processes generated from within and between the families themselves.

\section{REFERENCES}

Anyon, J. (1997). Ghetto schooling: A political economy of urban educational reform. New York: Teachers College Press.

Auerbach, S. (2010). Beyond coffee with the principal: Toward leadership for authentic school-family partnerships. Journal of School Leadership, 20(6), 728-757.

Bamberg, M. (2004). Considering counter-narratives. In M. Bamberg \& M. Andrews (Eds.), Considering counter-narratives: Narrating, resisting, making sense (pp. 351-371). John Benjamins e-Platform. https://doi.org/10.1075/sin.4

Banks, J. (1981). Multiethnic education: Theory and practice. Retrieved from https://eric.ed.gov/?id=ED300474

Black, R., Sprague, A., \& New America. (2016). The rise and reign of the welfare queen. The Atlantic. Retrieved from https://www.theatlantic.com/business/archive/2016/09/welfare-queen-myth/ 501470/

Blumenkrantz, D. G., \& Wasserman, D. L. (1998). What happens to a community intervention when the community doesn't show up? Restoring rites of passage as a consideration for contemporary community intervention. Family Science Review, 11, 239-258.

Chirkov, V. I., M Ryan, R., \& Sheldon, K. M. (2011). Human autonomy in cross-cultural context: Crosscultural advancements in positive psychology 1 (Vol. 1). Springer, Dordrecht. https://doi.org/10.1007/978-90-481-9667-8

Christenson, S., Reschly, A. L., \& Wylie, C. (2012). Handbook of research on student engagement. Springer. https://doi.org/10.1007/978-1-4614-2018-7

Darling-Hammond, L. (2010). the flat world and education: How America's commitment to equity will determine our future (multi-cultural education series). New York: Teachers College Press.

Deci, E. L., \& Ryan, R. M. (2000). The "what" and "why" of goal pursuits: Human needs and the selfdetermination of behavior. Psychological Inquiry, 11(4), 227. https://doi.org/10.1207/ S15327965PLI1104_01

Domina, T. (2005). Leveling the home advantage: Assessing the effectiveness of parental involvement in elementary school. Sociology of Education. https://doi.org/10.1177/003804070507800303

Durden, T. (2008). Do your homework! Investigating the role of culturally relevant pedagogy in comprehensive school reform models serving diverse student populations. Urban Review, 40(4), 403-419. https://doi.org/10.1007/s11256-008-0086-x

Epstein, J. L. (1981). The quality of school life. Lexington Books. Retrieved from https://eric.ed.gov/?id=ED205647

Epstein, J. L., Sanders, M., Simon, B., Salinas, K., Jansorn, N., VanVoorhis, F., \& Oaks, C. A. (2009). School, family, and community partnerships: Your handbook for action. Thousand Oaks, CA: Corwin Press.

Goodall, J., \& Montgomery, C. (2014). Parental involvement to parental engagement: a continuum. Educational Review, 66(4), 399-410. https://doi.org/10.1080/00131911.2013.781576

Gordon, M. F., \& Louis, K. S. (2009). Linking parent and community involvement with student achievement: Comparing principal and teacher perceptions of stakeholder influence. American Journal of Education, 116(1), 1-31. https://doi.org/10.1086/605098

Grolnick, W. S. (2015). Mothers' motivation for involvement in their children's schooling: Mechanisms and outcomes. Motivation and Emotion, 39(1), 63-73. https://doi.org/10.1007/s11031-014-9423-4

Grolnick, W. S., \& Raftery-Helmer, J. N. (2015). Core components of family-school connections: Toward a model of need satisfying partnerships. In Foundational aspects of family-school partnership research (pp. 15-34). Cham: Springer International Publishing. https://doi.org/10.1007/978-3-31913838-1_2

Hill Jr., P. (1992). Coming of age: African American male rites-of-passage. Chicago, IL: African American 
Images.

Hornby, G., \& Lafaele, R. (2011). Barriers to parental involvement in education: an explanatory model. Educational Review, 63(1), 37-52. https://doi.org/10.1080/00131911.2010.488049

Howard, T. C. (2010). Why race and culture matter in schools: Closing the achievement gap in America's classrooms (Multi-cultural education series). New York: Teachers College Press.

Jeynes, W. H. (2011). Help families by fostering parental involvement. The Phi Delta Kappan, 93(3), 3839. https://doi.org/10.1111/j.1475-682X.2001.tb01110.x

Jeynes, W. H. (2016). A Meta-analysis: The relationship between parental involvement and African American school outcomes. Journal of Black Studies, 47(3), 195-216. https://doi.org/ $10.1177 / 0021934715623522$

Koestner, R., \& Losier, G. F. (1996). Distinguishing reactive versus reflective autonomy. Journal of Personality, 64(2), 465. https://doi.org/10.1046/j.1420-9101.1995.8050575.x

Ladson-Billings, G. (2009). The dreamkeepers: Successful teachers of African American children (2nd ed.). San Francisco: Jossey-Bass. https://doi.org/10.2307/2077209

Little, T. D., Snyder, C. R., \& Wehmeyer, M. L. (2006). The agentic self: On the nature and origins of personal agency across the lifespan. In D. Mroczek \& T. D. Little (Eds.), Handbook of personality development (pp. 23-37). Lawrence Erlbaum Associates.

Potter, D., \& Morris, D. S. (2017). Family and schooling experiences in racial/ethnic academic achievement gaps. Sociological Perspectives, 60(1), 132-167. https://doi.org/10.1177/ 0731121416629989

Reilly, K. (2016). Here are all the times Donald Trump insulted Mexico. Time Magazine. Retrieved from http://time.com/4473972/donald-trump-mexico-meeting-insult/

Ryan, R. M. (1995). Psychological needs and the facilitation of integrative processes. Special Issue: Levels and Domains in Personality, 63(3), 397-427.

Ryan, R. M., \& Deci, E. L. (2011). A self-determination theory perspective on social, institutional, cultural, and economic supports for autonomy and their importance for well-being. In V. I. Chirkov, R. M. Ryan, \& K. M. Sheldon (Eds.), Human autonomy in cross-cultural context (pp. 45-64). Springer, Dordrecht. https://doi.org/10.1007/978-90-481-9667-8_3

Ryan, R. M., \& Deci, E. L. (2017). Self-determination theory: Basic psychological needs in motivation, development, and wellness. New York: Guilford Press.

Sabater, A. (2014). Tellin' children our story: A fun technique for teaching history, culture and selfempowerment. Washington, D.C.: Arena Press.

Shogren, K. A., Wehmeyer, M. L., \& Palmer, S. B. (2017). Causal agency theory. In M. L. Wehmeyer, K. A. Shogren, T. D. Little, \& S. J. Lopez (Eds.), Development of self-determination through the lifecourse (pp. 55-67). Dordrecht: Springer Netherlands. https://doi.org/10.1007/978-94-024-1042-6_5

Shogren, K. A., Wehmeyer, M. L., Palmer, S. B., Forber-Pratt, A. J., Little, T. J., \& Lopez, S. (2015). Causal agency yheory: Reconceptualizing a functional model of self-determination. Education and Training in Autism and Developmental Disabilities, 50, 251-263. https://doi.org/ $10.2307 / 24827508$

Sleeter, C. E. (1991). Empowerment through Multicultural Education. State University of New York Press.

Torre, D., \& Murphy, J. (2016). Communities of parental engagement: New foundations for school leaders work. International Journal of Leadership in Education. https://doi.org/10.1080/ 13603124.2014.958200

van Gennep, A. (1960). Rites of passage (2004 ed.). London: Routledge.

Wasserman, D. L. (2010). Using a systems orientation and foundational theory to enhance theory-driven human service program evaluations. Evaluation and Program Planning, 33, 67-80. https://doi.org/10.1016/j.evalprogplan.2009.06.005

Wasserman, D. L., \& Hill, F. (2016). Tactics that work: African-American diaspora space families and guardians of the generations. Black Child Journal, Guardians of the Generations (Spring). Retrieved from http://nropi.org/books/

Wasserman, D. L., Sabater, A., \& Hill, F. (2017). Strengthening families: The Journey Project model for engaging low-income black families in children's education. Black Child Journal, Education and the Black Child, (Summer). Retrieved from http://nropi.org/books/ 
Wilder, S. (2016). Effects of parental involvement on academic achievement: A meta-synthesis. Education Review, 66(3), 377-377. https://doi.org/10.1080/00131911.2013.780009

DEBORAH WASSERMAN, PhD, is a Senior Research Associate at COSI's Lifelong Learning Group in Columbus, Ohio. She has functioned as the National Rites of Passage Institute's Evaluation Lead since 2010. Her program evaluation research focuses on using selfdetermination theory as direction for including typically marginalized voices in the program evaluation process.

AYIZE SABATER is a dynamic social entrepreneur, author and twenty-year White House awarded educator who has co-founded several non-profit organizations, including a Montessori Public Charter school. Mr. Sabater is currently a doctoral candidate in Urban Educational Leadership and his dissertation is exploring the relationship between parental involvement and urban student academic performance. Mr. Sabater's research interests include parental involvement, Montessori education for marginalized children, social entrepreneurship, and transformative community building work by faith based institutions. 